University of Nebraska - Lincoln

DigitalCommons@University of Nebraska - Lincoln

Faculty Publications: Department of Teaching, Department of Teaching, Learning and Teacher Learning and Teacher Education

Education

2012

\title{
Cardiovascular Fitness Moderates the Relations Between Estimates of Obesity and Physical Self-Perceptions in Rural Elementary School Students
}

\author{
Nathanael G. Mitchell \\ Spalding University, nmitchell01@spalding.edu \\ Justin B. Moore \\ University of South Carolina - Columbia, jusmoore@wakehealth.edu \\ Wendy S. Bibeau \\ University of Maryland - College Park, wbibeau@gmail.com \\ Kathleen Moritz Rudasill \\ University of Nebraska-Lincoln, kmrudasill@vcu.edu
}

Follow this and additional works at: https://digitalcommons.unl.edu/teachlearnfacpub

Part of the Other Teacher Education and Professional Development Commons

Mitchell, Nathanael G.; Moore, Justin B.; Bibeau, Wendy S.; and Rudasill, Kathleen Moritz, "Cardiovascular Fitness Moderates the Relations Between Estimates of Obesity and Physical Self-Perceptions in Rural Elementary School Students" (2012). Faculty Publications: Department of Teaching, Learning and Teacher Education. 136.

https://digitalcommons.unl.edu/teachlearnfacpub/136

This Article is brought to you for free and open access by the Department of Teaching, Learning and Teacher Education at DigitalCommons@University of Nebraska - Lincoln. It has been accepted for inclusion in Faculty Publications: Department of Teaching, Learning and Teacher Education by an authorized administrator of DigitalCommons@University of Nebraska - Lincoln. 


\title{
Cardiovascular Fitness Moderates the Relations Between Estimates of Obesity and Physical Self-Perceptions in Rural Elementary School Students
}

\begin{abstract}
Nathanael G. Mitchell, Justin B. Moore, Wendy S. Bibeau, and Kathleen M. Rudasill
Background: Levels of physical activity decline throughout childhood. Children's physical self-perceptions have been found to relate to their physical activity. Understanding the relationships among physical selfperceptions, obesity, and physical activity could have important implications for interventions in children. Methods: The current study investigated the moderating effect of cardiovascular fitness (CVF, heart rate recovery from a 3-minute step test) on the relationship between obesity (BMI, waist circumference) and physical self-perceptions (athletic competence, physical appearance) in 104 fourth- and fifth-grade children from a small rural community. Results: Hierarchical regression analyses indicated that CVF moderated the relations between BMI and waist circumference on athletic competence. For children with lower fitness, higher waist circumference was associated with lower athletic competence, while for children with higher fitness levels, higher BMI was associated with higher athletic competence. Results also indicated that both BMI and waist circumference were negatively related to physical appearance. CVF moderated these relations such that only children with lower fitness, greater BMI and waist circumference was associated with poorer physical appearance scores. Conclusions: Implications include the need for support of fitness programs to promote psychological well-being and to investigate the relationship between obesity and physical self-perceptions within the context of fitness.
\end{abstract}

Keywords: body composition, exercise psychology, pediatrics, physical fitness

Children's physical activity levels have declined steadily over the last several decades. ${ }^{1}$ Physical activity declines dramatically during late childhood and preadolescence, with the declines especially pronounced in females. ${ }^{2-4}$ Researchers have posited that to develop effective physical activity interventions for children, an understanding of psychological and cognitive variables related to physical activity must be investigated. ${ }^{5,6}$ Further, the social cognitive theory (SCT) ${ }^{7}$ is an oft cited theory when addressing physical activity and health behaviors in children. A core element of SCT is reciprocal determinism, which states that there are constant, dynamic, causal interactions between a child's environmental, behavioral, and personal factors. Children's

Mitchell is with the School of Professional Psychology, Spalding University, Louisville, KY. Moore is with the Dept of Health Promotion, Education, and Behavior, Arnold School of Public Health, University of South Carolina, Columbia, SC. Bibeau is with the Dept of Biostatistics and Epidemiology, School of Public Health, University of Maryland, College Park, MD. Rudasill is with the Dept of Educational Psychology, College of Education and Human Sciences, University of Nebraska, Lincoln, NE. self-perceptions (eg, self-efficacy, outcome expectations) are integral in influencing their choice to initiate and maintain physical activity. Indeed, previous research has a found a link between children's physical self-perceptions and their physical activity, such that more positive physical self-perceptions are related to higher levels of physical activity. In addition, Dishman and colleagues ${ }^{8}$ found a direct causal link between social-cognitive variables and an increase in physical activity in adolescent girls. Further research is needed to understand the relations between children's self-perceptions, physical activity, and body size.

The increasing prevalence of obesity in children in the U.S. has become a major public health concern, as prevalence rates across all age groups continue to increase. The percentage of overweight children age 6 to 11 years rose from $28.2 \%$ in 1999 to $33.6 \%$ by 2004. ${ }^{9}$ Research suggests that rural children may be at particular risk for obesity. ${ }^{10-12}$ According to the " $\mathrm{F}$ as in Fat" Report, Kentucky ranks fourth in the United States for prevalence of overweight and obese youth age 10 to 17 years, impacting nearly $37.1 \%$ of the population of children in this age range. It is important to study the physical and psychological variables that may assist in developing programs to decrease obesity in such highrisk populations. 
Research indicates children's obesity is related to how they feel about themselves physically, ${ }^{13,14}$ with heavier children reporting poorer perceptions of their athletic abilities and physical appearance. ${ }^{13-20}$ Despite the prevalence and increased risk of obesity in rural communities, few studies have been conducted to investigate the relationship between estimates of obesity and self-perceptions among rural children. Related to self-perceptions of physical appearance, Packard and Krogstrand ${ }^{21}$ investigated the weight concerns of girls age 8 to 17 from rural communities in the Midwest. Their results indicated that more than $60 \%$ of girls age 8 to 10 expressed weight concerns, specifically the desire to be thinner. Welch and coworkers ${ }^{22}$ examined the relation between body image perceptions and obesity, as measured by BMI, in a sample of fourth graders in Maryland. The schoolchildren were sampled from urban, suburban, and rural locations. When comparing those who were categorized as overweight with their healthy weight peers, rural students expressed more body dissatisfaction than urban students. These few studies represent the beginnings of a necessary line of research investigating the relationship between estimates of obesity and the physical self-perceptions of children at greater risk of obesity due to their particular geographic location.

In addition, in a recent literature review of the psychological impact of obesity in children, Wardle and Cook $^{23}$ questioned the lack of consistency and small effect sizes in previous research investigating the link between children's obesity and self-perceptions. One possible explanation for inconsistent findings linking these constructs may be the use of BMI as the primary estimate of obesity. BMI may not reflect a child's true physical condition because BMI does not accurately distinguish between lean muscle mass and fat mass, nor does it reveal distribution of obesity. In an effort to better assess fat distribution and its potential health effects, medical and physiological researchers often use other indicators of obesity such as waist circumference when examining associations between obesity and disease risk factors. ${ }^{24-26}$ Furthermore, the measurement error associated with BMI may not allow researchers to fully understand the relationship between the physical condition of a child and his or her physical self-perceptions. For example, the impact of obesity on self-perceptions for a child with a large belly that is disproportionate to the rest of his or her body may be different from a child who is large but proportioned more evenly and comparably to his or her peers. Therefore, the current study employs 2 measures of obesity: BMI and waist circumference. Wardle and $\mathrm{Cook}^{23}$ urged researchers to examine possible moderators of the relation between children's obesity and psychological functioning, including self-perceptions. One such potential moderator may be children's cardiovascular fitness (CVF). Children's CVF has been shown to contribute to children's physical self-perceptions. Husenblaus and colleagues ${ }^{27}$ found a significant relationship between cardiovascular fitness and evaluations of the physical self; specifically, children with lower CVF levels reported lower satisfaction with themselves physically. Similarly, a study revealed that a physical fitness intervention with fourth-grade Hispanic children increased children's fitness and improved physical self-perceptions. ${ }^{28}$ These studies represent the small body of literature linking CVF to children's physical self-perceptions. However, there is a dearth of literature considering the cardiovascular fitness of children as a potential moderator of the relationship between estimates of obesity and children's physical self-perceptions.

The link between estimates of obesity and children's physical perceptions may contrast greatly depending on children's cardiovascular fitness. The physical self-perceptions of a child who is both fit and has higher estimates of obesity (eg, a football player on the offensive line) may contrast greatly with the physical self-perceptions of a child who is less fit and also has high estimates of obesity. Having higher estimates of obesity may have a more negative impact on physical self-perceptions for a child who becomes out of breath after climbing a flight of stairs compared with a child who is able to play sports or join his or her friends in physically challenging activities. It is also particularly important to understand this relationship for children who, for various reasons, are at higher risk for obesity. Children in rural areas of Kentucky comprise such an at-risk sample.

Therefore, the current study seeks to understand the relationships between various estimates of obesity, children's physical self-perceptions, and the moderating effect of cardiovascular fitness on these relationships in rural elementary school children. The current study was designed to test examine the following research questions and test the following hypotheses: First, are BMI and, waist circumference associated with rural children's physical self-perceptions (ie, athletic competence, physical appearance)? It was hypothesized that both estimates of obesity (ie, BMI, waist circumference) would have significant, negative relationships with physical self-perceptions. Second, does cardiovascular fitness moderate relations between the 2 estimates of obesity and children's physical self-perceptions? It was hypothesized that CVF would be a moderator of the relation between estimates of obesity and physical self-perceptions.

\section{Methods}

\section{Participants}

A sample of 104 (48 male, 56 female, $99 \%$ white) children from grades 4 and 5 (age range $=9-12$ yrs, mean $=$ $10.70 \mathrm{yrs}$ ) were recruited from an elementary school in a small rural community in Kentucky. Participants were recruited via packets sent home to parents through homeroom teachers. This resulted in an acceptable response rate of approximate $55 \%$ of children, enrolled in grades 4 and 5. Children who returned signed consent forms were called from class in groups of 5 to the nurse's office 
where 2 different methods commonly used for estimating obesity as well as a measure of cardiovascular fitness were collected by properly trained exercise physiologists and health educators. In addition, after providing informed assent, participants completed a questionnaire to measure self-perceptions. Table 1 presents the correlation matrix, including means and standard deviations, for all variables included in the analysis. All procedures were reviewed by an institutional review board, and were approved to meet all ethical guidelines concerning human subjects research.

\section{Instruments and Physiological Measures}

Self-Perception Profile for Children. The Self-Perception Profile for Children ${ }^{29}$ (SPPC) is one of the most widely used instruments to measure self-perceptions of children. The SPPC is a 36-item scale that measures children's domain-specific perceptions of their competence, and assesses global perception of self-worth. ${ }^{30}$ The SPPC contains 5 6-item subscales encompassing multiple facets of the self. For the current study, only scores from the Athletic Competence (AC), and Physical Appearance (PA) subscales were collected to obtain children's physical self-perceptions. Studies have shown the SPPC to have adequate internal consistency. Acceptable internal consistency has been reported for children in third to fifth grade with Cronbach's alpha of .80 for AC and .80 for PA. ${ }^{29}$ With the current sample, Cronbach's alpha was .80 for $\mathrm{AC}$ and .83 for PA.

Body Mass Index (BMI) was calculated by dividing weight in kilograms by the square of height in meters $\left(\mathrm{kg} / \mathrm{m}^{2}\right)$. Height and weight was measured twice, using a Seca 225 Height Rod stadiometer, and rounded to the nearest $0.1 \mathrm{~kg}$ and $\mathrm{cm}$, respectively.

Waist Circumference (WC) was collected as an estimate of central obesity. WC was rounded to the nearest $0.1 \mathrm{~cm}$, was taken twice at the narrowest point of the waist using a Gulick tape measure. Both measurements were then averaged to create a final WC value.

Cardiovascular Fitness. Cardiovascular fitness (CVF) was assessed based on the results of a submaximal cardiovascular fitness test. A YMCA step test protocol was used to assess the cardiovascular fitness of participants. ${ }^{31}$ The step test protocol required the participant to step up and down on a 12 inch bench at a rate of 24 steps per minute for 3 minutes. Heart rate was monitored continuously throughout the test using a Polar heart rate monitor. Heart rate was recorded immediately upon cessation of the test $\left(\mathrm{t}_{0}\right)$, and at $1\left(\mathrm{t}_{1}\right)$ and 2 minutes $\left(\mathrm{t}_{2}\right)$ posttest. The heart rate recorded immediately following the YMCA step test has been used by researchers in similar studies of children and has shown to be responsive to changes in fitness resulting from increases in physical activity. ${ }^{32,33}$

\section{Data Analysis}

Two series of hierarchical regression analyses were conducted. In the first series, athletic competence was regressed on each obesity measure separately. In the second series, physical appearance was regressed on each obesity measure separately. Since the raw BMI score was used, which is unadjusted for age and gender, the relationship between gender and the 2 physical self-perception subscales was investigated to determine whether the effects of gender should be controlled for in the analyses. Because gender was not significantly related to athletic competence, it was not entered into the regression analyses predicting athletic competence. Thus, the obesity measure was entered in the first step as a risk factor; CVF was entered into the second step as a protective factor; and 2-way interactions between CVF and obesity measures were entered into the third step. For the second series of hierarchical regressions, gender was significantly related to physical appearance; therefore, it was entered in the first step of the regression. The obesity measure was entered into the second step. CVF was entered into the third step. Finally, 2-way interactions between CVF and obesity measures were entered into the fourth step.

\section{Results}

\section{Athletic Competence}

Results of the hierarchical regressions with BMI and waist circumference on athletic competence are displayed in Table 2 . As expected, waist circumference significantly explained variance in athletic competence $\left(R^{2}=.058, P<\right.$ $.05)$; however, BMI was not significantly associated with athletic competence $\left(R^{2}=.023, P=.063\right)$. In the second

Table 1 Mean, Standard Deviation, and Correlations for BMI, Waist Circumference, Athletic Competence, Physical Appearance, and Cardiovascular Fitness

\begin{tabular}{lccccccc}
\hline Variable & Mean & SD & $\mathbf{1}$ & $\mathbf{2}$ & $\mathbf{3}$ & $\mathbf{4}$ & $\mathbf{5}$ \\
\hline 1. BMI & 20.8 & 4.1 & 1.0 & $.92^{* *}$ & -.11 & $-.26^{* *}$ & $-.45^{* *}$ \\
2. Waist circumference & 65.9 & 10.5 & & 1.0 & -.20 & $-.26^{* *}$ & $-.46^{* *}$ \\
3. Athletic competence & 17.1 & 3.1 & & & 1.0 & $.27^{* *}$ & $.39^{* *}$ \\
4. Physical appearance & 17.2 & 3.6 & & & 1.0 & $.25^{* *}$ \\
5. Cardiovascular fitness & 1.5 & .26 & & & & 1.0 \\
\hline
\end{tabular}

$* P<.05 ; * * P<.01$. 
step, CVF accounted for a significant amount of variance in athletic competence over and above the relationship with obesity (BMI: $\Delta R^{2}=.138, P<.01$; WC: $\Delta R^{2}=.107$, $P<.01)$. Finally, in the third step the 2 -way interaction between fitness and obesity significantly explained variance over and above the independent association with both obesity and fitness (BMI: $\Delta R^{2}=.032, P<.05$; WC: $\left.\Delta R^{2}=.035, P<.05\right)$.

Following criteria established by Baron and Kenny (1986), 2 subsequent steps were performed to test if the association between the independent variable and the dependent variable varied as a function of the moderator. First, the moderating variable (ie, CVF) was changed from a continuous variable to a categorical variable. Specifically, CVF was split into 2 categories, 'low' and 'high,' using a median score cut-point. Second, regression analyses were used to examine the association between the obesity variable and athletic competence among individuals with low and high CVF scores. For both fitness groups, separate analyses were conducted regressing athletic competence on BMI and waist circumference (see Table 3). Results indicated that CVF moderated the relation between $\mathrm{BMI}$ and athletic competence, with higher BMI associated with greater athletic competence for the "high fitness" group. Conversely, CVF moderated the relation between waist circumference and athletic competence, such that higher waist circumference was associated with lower athletic competence for the "low fitness" group. Put another way, children in the high fitness group with higher BMI scores were more likely to have higher athletic competence scores. On the other hand, children in the low fitness group with higher WC scores were more likely to have lower athletic competence scores.

\section{Physical Appearance}

Results of the hierarchical regression of BMI and waist circumference on physical appearance can be seen in Table 4. As expected, both BMI and waist circumference had significant negative relationships with physical appearance, over and above the relationship with gender (BMI: $\Delta R^{2}=.040, P<.05$; WC: $\Delta R^{2}=.055, P<.05$ ). In the third step, no significant variance was explained by CVF with either obesity measure (BMI: $\Delta R^{2}=.016, P$ $>.05$; WC: $\left.\Delta R^{2}=.010, P>.05\right)$. In the fourth step, the 2-way interaction between obesity and fitness explained significant variance in physical appearance, controlling for gender and main effects (BMI: $\Delta R^{2}=.036, P<.05$; WC: $\left.\Delta R^{2}=.033, P<.05\right)$.

To demonstrate the nature of the interaction, we used CVF groups as described above. For both fitness groups, separate linear regressions were then conducted on physical appearance for both BMI and waist circumference (see Table 5). The results indicated that for both BMI and waist circumference, there were significant negative relationships between obesity and physical appearance for only the low fitness group.

Table 2 Hierarchical Regression Analysis With Athletic Competence as the Dependent Variable

\begin{tabular}{|c|c|c|c|c|c|c|c|c|c|c|}
\hline & \multicolumn{5}{|c|}{ BMI } & \multicolumn{5}{|c|}{ Waist circumference } \\
\hline & $B$ & SEB & $\beta$ & $R^{2}$ & $\Delta R^{2}$ & $B$ & SEB & $\beta$ & $R^{2}$ & $\Delta R^{2}$ \\
\hline Block 1 & & & & .023 & & & & & $.058 * *$ & \\
\hline Adiposity & -.160 & .104 & -.153 & & & -.099 & .040 & $-.241 * *$ & & \\
\hline Block 2 & & & & $.161 * * *$ & $.138 * *$ & & & & $.165 * * *$ & $.107 * *$ \\
\hline Fitness & 7.01 & 1.74 & $.414 * * *$ & & & 6.22 & 1.76 & $.367 * *$ & & \\
\hline Block 3 & & & & $.193 * * *$ & $.032 *$ & & & & $.200 * * *$ & $.035^{*}$ \\
\hline Adiposity $\times$ fitness & .670 & .343 & $.931 *$ & & & .293 & .143 & $1.15^{*}$ & & \\
\hline
\end{tabular}

$* P<.05 ; * * P<.01 ; * * * P<.001$.

Table 3 Linear Regression Analysis With Athletic Competence as Dependent Variable by Cardiovascular Fitness Group

\begin{tabular}{|c|c|c|c|c|c|c|c|c|}
\hline & \multicolumn{4}{|c|}{ BMI } & \multicolumn{4}{|c|}{ Waist circumference } \\
\hline & $B$ & SEB & $\beta$ & $R^{2}$ & $B$ & SEB & $\beta$ & $R^{2}$ \\
\hline Low fitness & & & & .046 & & & & $105^{*}$ \\
\hline Adiposity & -.217 & .139 & -.215 & & -.128 & .053 & $-.324 *$ & \\
\hline High fitness & & & & $.096^{*}$ & & & & .067 \\
\hline Adiposity & .417 & .186 & $.310 *$ & & .141 & .077 & .258 & \\
\hline
\end{tabular}

$* P<.05 ; * * P<.01 ; * * * P<.001$. 
Table 4 Hierarchical Regression With Physical Appearance as Dependent Variable

\begin{tabular}{|c|c|c|c|c|c|c|c|c|c|c|}
\hline & \multicolumn{5}{|c|}{ BMI } & \multicolumn{5}{|c|}{ Waist circumference } \\
\hline & $B$ & SEB & $\beta$ & $R^{2}$ & $\Delta \boldsymbol{R}^{2}$ & $B$ & SEB & $\beta$ & $R^{2}$ & $\Delta R^{2}$ \\
\hline Block 1 & & & & $.041 *$ & & & & & $.041^{*}$ & \\
\hline Gender & 1.87 & .904 & $.202 *$ & & & 1.87 & .904 & $.202 *$ & & \\
\hline Block 2 & & & & $.081 *$ & $.04 *$ & & & & $.096 * *$ & $.055^{*}$ \\
\hline Adiposity & -.229 & .109 & $-.202 *$ & & & -.104 & .042 & $-.235^{*}$ & & \\
\hline Block 3 & & & & $.097 *$ & .016 & & & & $.106^{*}$ & .01 \\
\hline Fitness & 2.57 & 1.93 & .145 & & & 2.12 & 1.97 & .120 & & \\
\hline Block 4 & & & & $.134 * *$ & $.036^{*}$ & & & & $.139 * *$ & $.033^{*}$ \\
\hline Adiposity $\times$ fitness & .767 & .377 & $.990 *$ & & & .306 & .159 & $1.13 *$ & & \\
\hline
\end{tabular}

$* P<.05 ; * * P<.01 ; * * * P<.001$.

Table 5 Linear Regression Analysis With Physical Appearance as Dependent Variable by Cardiovascular Fitness Group

\begin{tabular}{|c|c|c|c|c|c|c|c|c|}
\hline & \multicolumn{4}{|c|}{ BMI } & \multicolumn{4}{|c|}{ Waist circumference } \\
\hline & $B$ & SEB & $\beta$ & $R^{2}$ & B & SEB & $\beta$ & $R^{2}$ \\
\hline Low fitness & & & & $.097 *$ & & & & . 099* \\
\hline Adiposity & -.327 & .141 & $-.311 *$ & & -.130 & .055 & $-.315^{*}$ & \\
\hline High fitness & & & & .006 & & & & .007 \\
\hline Adiposity & -.123 & .232 & -.075 & & .055 & .095 & .082 & \\
\hline
\end{tabular}

$* P<.05 ; * * P<.01 ; * * * P<.001$.

\section{Discussion}

The main finding of this study is the moderating role of CVF between the relations of 2 different markers of obesity and children's physical self-perceptions. To our knowledge, this is the first study examining CVF's moderating role between these variables. A major strength of the current paper was the use of an objective measure of CVF. The consistency and scale of the moderating effect of fitness on the relationship between obesity and both physical appearance and athletic competence is compelling.

Concerning children's evaluations of their athletic competence, CVF moderated associations between obesity and athletic competence. CVF played different moderating roles depending on obesity measure. For BMI, there was a positive relationship between obesity and athletic competence, but only for those children who were more physically fit. That is, children who were larger and more physically fit had increased likelihood of better evaluations of their athletic abilities. Concerning waist circumference, the moderating effect of CVF revealed that children with larger waists had lower evaluations of athletic competence, but only among those who were less fit. In both instances, those with higher CVF had no negative relationships between the obesity measure and athletic competence.

The results have clear implications for the engagement and maintenance of physical activity within the context of athletic activities. Late childhood is a developmental period in which significant declines in physical activity have been observed, especially in girls. ${ }^{4}$ While the focus of many childhood obesity interventions are to decrease BMI, ${ }^{34,35}$ the results of this study imply that an emphasis in increasing cardiovascular fitness may be more beneficial in maintaining positive attitudes about athletic abilities.

Consistent with previous literature, the results reported here indicate that estimates of obesity negatively relate to children's evaluations of their physical appearance, ${ }^{13-16}$ such that BMI and waist circumference were significant risk factors for poorer evaluations of their appearance. CVF consistently moderated associations between both measures of obesity and physical appearance. Specifically, for those who had higher CVF, BMI and waist circumference were no longer negatively associated with self-perceptions of physical appearance. In addition, for those with lower CVF, there was a negative association between obesity and self-perceptions of physical appearance. These results indicate that interventions 
designed to increase and maintain physical activity and cardiovascular fitness may have the additional benefit of increasing children's satisfaction with their physical appearance.

The findings of the current study should be interpreted in light of its limitations. First, because the study design is not experimental or longitudinal, causality cannot be inferred. Another important aspect to be considered is the sample used in the study. Specifically, findings from this study may not be generalizable to nonrural community samples. Cultural norms and expectations in the rural community could be additional moderators of the relationship between obesity and self-perceptions that were not investigated in the current study. Similar explorations into the moderating effect of fitness level on the relation between obesity and physical self-perceptions, should sample children from several geographic locations.

The current results may have implications for both prevention and intervention programs. Previous research concerning CVF in adults indicates that small improvements in CVF, especially those with lower CVF, can have great impact on chronic disease morbidity and mortality. ${ }^{36-38}$ In the current study, low fitness was associated with greater risk of poor physical self-perceptions. It is plausible that the positive results found improving the CVF of adults with low CVF may also be found to have both physical and psychological benefits for children. Therefore, interventions that increase physical activity enough to have even small improvements in CVF may prove fruitful.

The study indicates that CVF may protect against obesity's association with psychological variables that could influence engagement in physical activity. The results of the investigation into the relationship between athletic competence and obesity indicate that understanding the distribution of fat may be more helpful in accurately understanding these relationships. Whenever possible, researchers concerned with the relations among obesity and psychological functioning should include CVF to better understand the relations between obesity and children's physical self-perceptions.

\section{Acknowledgments}

This project was supported by a grant from the Purchase Area Health Education Center (JBM, PI). The support of Loretta I. Maldaner (Director, Purchase AHEC) and the Crittenden County Elementary School were essential to completion of this project.

\section{References}

1. Adams J. Trends in physical activity and inactivity amongst US 14-18 year olds by gender, school grade and race, 1993-2003: evidence from the youth risk behavior survey. BMC Public Health. 2006;6:57.
2. Caspersen CJ, Pereira MA, Curran KM. Changes in physical activity patterns in the United States, by sex and crosssectional age. Med Sci Sports Exerc. 2000;32(9):16011609.

3. Kimm SY, Glynn NW, Kriska AM, et al. Longitudinal changes in physical activity in a biracial cohort during adolescence. Med Sci Sports Exerc. 2000;32(8):1445-1454.

4. Kimm SY, Glynn NW, Kriska AM, et al. Decline in physical activity in black girls and white girls during adolescence. N Engl J Med. 2002;347(10):709-715.

5. Dishman RK, Motl RW, Saunders R, et al. Self-efficacy partially mediates the effect of a school-based physicalactivity intervention among adolescent girls. Prev Med. 2004;38(5):628-636.

6. Ransdell LB, Dratt J, Kennedy C, O’Neill S, DeVoe D. Daughters and Mothers Exercising Together (DAMET): a 12-week pilot project designed to improve physical self-perception and increase recreational physical activity. Women Health. 2001;33(3):113-129.

7. Bandura A. Self-efficacy: toward a unifying theory of behavioral change. Psychol Rev. 1977;84(2):191-215.

8. Dishman RK, Hales DP, Pfeiffer KA, et al. Physical selfconcept and self-esteem mediate cross-sectional relations of physical activity and sport participation with depression symptoms among adolescent girls. Health Psychol. 2006;25(3):396-407.

9. Ogden CL, Carroll MD, Curtin LR, McDowell MA, Tabak CJ, Flegal KM. Prevalence of overweight and obesity in the United States, 1999-2004. JAMA. 2006;295(13):15491555.

10. Harrell TK, Davy BM, Stewart JL, King DS. Effectiveness of a school-based intervention to increase health knowledge of cardiovascular disease risk factors among rural Mississippi middle school children. South Med J. 2005;98(12):1173-1180.

11. Lewis RD, Meyer MC, Lehman SC, et al. Prevalence and degree of childhood and adolescent overweight in rural, urban, and suburban Georgia. J Sch Health. 2006;76(4):126-132.

12. Moore JB, Davis CL, Baxter SD, Lewis RD, Yin Z. Physical activity, metabolic syndrome, and overweight in rural youth. J Rural Health. 2008;24(2):136-142.

13. Eisenberg ME, Neumark-Sztainer D, Story M. Associations of weight-based teasing and emotional wellbeing among adolescents. Arch Pediatr Adolesc Med. 2003;157(8):733-738.

14. Gibson LY, Byrne SM, Blair E, Davis EA, Jacoby P, Zubrick SR. Clustering of psychosocial symptoms in overweight children. Aust N Z J Psychiatry. 2008;42(2):118125.

15. Davison KK, Birch LL. Weight status, parent reaction, and self-concept in five-year-old girls. Pediatrics. 2001;107(1):46-53.

16. Davison KK, Birch LL. Processes linking weight status and self-concept among girls from ages 5 to 7 years. Dev Psychol. 2002;38(5):735-748.

17. Vander Wal JS, Thelen MH. Predictors of body image dissatisfaction in elementary-age school girls. Eat Behav. 2000;1(2):105-122.

18. Duncan MJ, Al-Nakeeb Y, Nevill AM. Body esteem and body fat in British school children from different ethnic groups. Body Image. 2004;1(3):311-315. 
19. Stein RJ, Bracken BA, Haddock CK, Shadish WR. Preliminary development of the Children's Physical Self-Concept Scale. J Dev Behav Pediatr. 1998;19(1):1-8.

20. Sung RYT, Yu CW, So RCH, Lam PKW, Hau KT. Self-perception of physical competences in preadolescent overweight Chinese children. Eur J Clin Nutr. 2004;59(1):101-106.

21. Packard P, Krogstrand KS. Half of rural girls aged 8 to 17 years report weight concerns and dietary changes, with both more prevalent with increased age. J Am Diet Assoc. 2002;102(5):672-677.

22. Welch C, Gross SM, Bronner Y, Dewberry-Moore N, Paige DM. Discrepancies in body image perception among fourth-grade public school children from urban, suburban, and rural Maryland. J Am Diet Assoc. 2004;104(7):1080 1085.

23. Wardle J, Cooke L. The impact of obesity on psychological well-being. J Clin Endocrinol Metab. 2005;19(3):421440.

24. Andersen LB, Sardinha LB, Froberg K, Riddoch CJ, Page AS, Anderssen SA. Fitness, fatness and clustering of cardiovascular risk factors in children from Denmark, Estonia and Portugal: The European Youth Heart Study. Int J Pediatr Obes. 2008;3(Supp 1):58-66.

25. Freedman DS, Serdula MK, Srinivasan SR, Berenson GS. Relation of circumferences and skinfold thicknesses to lipid and insulin concentrations in children and adolescents: the Bogalusa Heart Study. Am J Clin Nutr. 1999;69(2):308-317.

26. Savva SC, Tornaritis M, Savva ME, et al. Waist circumference and waist-to-height ratio are better predictors of cardiovascular disease risk factors in children than body mass index. Int J Obes Relat Metab Disord. 2000;24(11):1453-1458.

27. Hausenblas HA, Symons Downs D, Fleming DS, Connaughton DP. Body image in middle school children. Eat Weight Disord. 2002;7(3):244-248.

28. Crews DJ, Lochbaum MR, Landers DM. Aerobic physical activity effects on psychological well-being in low-income Hispanic children. Percept Mot Skills. 2004;98(1):319_ 324.
29. Harter S. Self-perception profile for children. Denver: CO University of Denver Press; 1985.

30. Harter S. The Perceived Competence Scale for Children. Child Dev. 1982;53(1):87-97.

31. Golding LA. YMCA fitness testing and assessment manual. 4 ed. Champaign, IL: Human Kinetics; 2000.

32. Trevino RP, Yin Z, Hernandez A, Hale DE, Garcia OA, Mobley C. Impact of the Bienestar school-based diabetes mellitus prevention program on fasting capillary glucose levels: a randomized controlled trial. Arch Pediatr Adolesc Med. 2004;158(9):911-917.

33. Yin Z, Moore JB, Johnson MH, et al. The Medical College of Georgia Fitkid project: the relations between program attendance and changes in outcomes in year 1. Int J Obes. 2005;29(Suppl 2):S40-S45.

34. Carrel AL, Clark RR, Peterson SE, Nemeth BA, Sullivan J, Allen DB. Improvement of fitness, body composition, and insulin sensitivity in overweight children in a schoolbased exercise program: a randomized, controlled study. Arch Pediatr Adolesc Med. 2005;159(10):963-968.

35. Lazaar N, Aucouturier J, Ratel S, Rance M, Meyer M, Duché P. Effect of physical activity intervention on body composition in young children: influence of body mass index status and gender. Acta Paediatr. 2007;96(9):13151320.

36. Blair SN, Jackson AS. Physical fitness and activity as separate heart disease risk factors: a meta-analysis. Med Sci Sports Exerc. 2001;33(5):762-764.

37. Blair SN, Kohl HW, 3rd, Barlow CE, Paffenbarger RS, $\mathrm{Jr}$, Gibbons LW, Macera CA. Changes in physical fitness and all-cause mortality. A prospective study of healthy and unhealthy men. JAMA. 1995;273(14):1093-1098.

38. Blair SN, Kohl HW, 3rd, Paffenbarger RS, Jr, Clark DG, Cooper KH, Gibbons LW. Physical fitness and all-cause mortality. A prospective study of healthy men and women. JAMA. 1989;262(17):2395-2401. 